\title{
The Moderation Effect of Social Support in the Relationship between Child Maltreatment and School Achievement
}

\author{
Rui Lopes \\ Psychology Department, Lisbon University Institute - ISCTE-IUL \\ Avenida das Forcas Armadas, 1649-026 Lisbon, Portugal \\ Tel: 351-2-1790-3216 E-mail: ruilopes79@hotmail.com \\ Carla Moleiro (Corresponding author) \\ Psychology Department, Lisbon University Institute - ISCTE-IUL \\ Avenida das Forcas Armadas, 1649-026 Lisbon, Portugal \\ \& \\ Centre for Psychological Research and Social Intervention - CIS \\ Tel: 351-2-1790-3216 E-mail: carla.moleiro@iscte.pt
}

Received: August 31, 2011

Accepted: October 9, $2011 \quad$ Published: December 30, 2011

doi:10.5539/jedp.v1n1p74

URL: http://dx.doi.org/10.5539/jedp.v1n1p74

\begin{abstract}
This study investigated the relationship between child maltreatment, school achievement and social support, by exploring the adaptation of the stress buffering model of social support. Data was collected on 402 children from $5^{\text {th }}-9^{\text {th }}$ grades ( 383 without history of child abuse and 64 with history of child abuse). An adapted version of the Social Support Appraisals Scale (Dubow \& Ullman, 1989; Dubow et al., 1991) was used to analyze the role of social support in the relationship between child maltreatment and school achievement. Results indicated that abused children scored lower in Language and Math, and had more grade retentions than children without history of abuse. Findings also revealed that perceived social support is a promoter of school achievement. Results also indicated social support as a moderator between child abuse and school achievement, although only partially in the direction of the adaptation of the stress buffering model. Implications for school professionals are discussed.
\end{abstract}

Keywords: Child maltreatment, Social support, School achievement, Moderation

\section{Introduction}

The consequences of child abuse are well documented (e.g., Finkelhor, 1995; Hildyard \& Wolfe, 2002; Lowenthal, 1998; Tyler, Johnson \& Brownridge, 2008) and despite possible identical consequences for any kind of abuse, different children may show different psychological and behavioral profiles (Barnett, Manly \& Cicchetti, 1993). Cicchetti and Toth (2005) highlighted a few possible consequences of child abuse, namely, difficulties in emotional regulation, in developing secure attachment relations, in establishing positive peer relations, in school adaptation and achievement, and in identity development and self-esteem.

School adjustment and academic performance constitute an area of concern and research among those that provide care for maltreated children (Kinard, 2001). One factor that seems to influence school adjustment is social support (Demaray, Malecki, Davidson, Hodgson \& Rebus, 2005). Social support is defined as the assistance and protection given to individuals (Langford, Bowsher, Maloney \& Lillis, 1997). The relationship between social support and children's behavioral and school adjustment has been studied concerning stressful life events. Dubow and Tisak (1989) found that a positive perceived social support and problem solving skills mediate the relationship between children's stressful life events and their school competencies and behavior.

Individual's social contexts can provide either stress or support, and different individuals show different receptiveness and ability in their use of available social support (Kaul \& Lakey, 2003; Lakey \& Cassady, 1990). 
In fact, stress in life events can result in the deterioration of perceived social support which, in turn, relates with increased psychological suffering. Several authors (e.g., Frazier. Tix, Klein \& Arikian, 2000) have found that social support can be of use in critical moments because it protects individuals from the adverse effects of stress. Social support was already found to attenuate the stress caused by child abuse (Runtz \& Schallow, 1997). However, the results found in some studies also suggest that abused children present lower levels of perceived social support (e.g., Muller, Gragtmans \& Baker, 2008). On the other hand, social support is beneficial for the adjustment of at-risk children, as well as for abused children's development and psychological wellbeing (e.g., Demaray \& Malecki, 2002b), possibly making a positive difference in their adaptability and resilience (Jafee, Caspi, Moffitt, Polo-Tomás, Taylor, 2007).

Studies have found that abused children's perceptions of support, as well as its benefits, vary according to its sources. For example, Ezzell, Swenson and Brondino (2000) found that physically abused children indicated their family, peers and teachers as sources of high social support. These authors concluded that, even in the presence of parental physical abuse, children may still feel that they are an important part of their family and that some members of the families care for them. Furthermore, both family and peer support (but not teacher support) appeared to predict children's symptomatology (anxiety, depression and aggressiveness). On the other hand, Kinard $(1999,2001)$ found a relationship between child abuse, school achievement and psychosocial resources available for children, such as social support. The results showed that abused children have poorer school achievement, as well as lower perceived social support, particularly from their mothers. Perceived social support from their friends and teachers did not reveal itself to be a significant predictor of school results. The relations found suggest the importance and need to intervene to improve school results and to develop abused children's and their families' social networks, as a way of promoting their adjustment.

Despite the extant literature in the field of child abuse (cf. Cicchetti \& Toth, 2005) and social support (cf. Langford et al., 1997), there lacks investigation that relates these two concepts and, specifically, that studies them in the scope of children's school achievement. This investigation intended to explore the relationship between child abuse, social support and school achievement, more specifically the adaptation of social support as a moderator of life stress model (see Frazier, Tix, Klein \& Arikian, 2000) to the specific context of child abuse and school achievement.

\section{Method}

\subsection{Participants}

A total of 402 children and adolescents from $5^{\text {th }}$ to $9^{\text {th }}$ grade from a public school in Lisbon, Portugal, participated in the study. Age range was comprehended between 9 and 18 years old $(M=12.76 ; S D=1.96)$. In terms of gender, $51 \%(n=205)$ were boys and $49 \%(n=197)$ were girls. Regarding ethnic origins, the majority was of Portuguese origin (60.9\%), followed by African (18.2\%), Brazilian (9.5\%), Asian (3.0\%), Central European (2.5\%), Eastern European (2.0\%) and South American (1.0\%). Socio-economic status was low for $43 \%$ of the families $(n=174)$, low average for $13 \%(n=51)$ and high average or above for $44 \%(n=177)$.

The participants were divided in two groups. In one group, participants were children and adolescents without history of abuse throughout their growth and development $(n=338 ; 84.1 \%)$, and in the other, participants were children and adolescents with a history of abuse $(n=64 ; 15.9 \%)$. All participants of the first group lived with their families. Participants of the second group either lived with their families or were followed by child protection services $(n=17 ; 4.2)$, or lived with their families having been referred to child protection services before $(n=17 ; 4.2 \%)$, or lived with their families having been in residential care $(n=8 ; 2.0 \%)$, or were in residential care $(n=22 ; 5.5 \%)$. Abuse histories included negligence $(n=23 ; 5.7 \%)$, physical abuse $(n=2 ; 0.5 \%)$, psychological abuse $(n=3 ; 0.7 \%)$, negligence and exposure to deviant behaviors $(n=12 ; 3.0 \%)$, negligence and physical abuse $(n=3 ; 0.7 \%)$, negligence and psychological abuse $(n=3 ; 0.7 \%)$, negligence and sexual abuse $(n$ $=1 ; 0.2 \%)$, and also physical and sexual abuse $(n=1 ; 0.2 \%)$. This group also included at-risk children that, although they did not have history of abuse per se, were in potentially harmful situations for their adjustment, namely, exposure to deviant behaviors (e.g., abuse of substances by the adults in the home; $n=14 ; 3.5 \%$ ) and domestic violence $(n=2 ; 0.5 \%)$ (Owen, Thompson \& Mitchell et al., 2008). Since some of the groups were too small, they were classified into four categories: 1$)$ children without history of abuse $(n=338)$; 2$)$ children exposed to risk $(n=16) ; 3)$ children with any history of negligence alone $(n=23)$; and 4$)$ children with any type of abuse, or combined abuse and negligence $(n=25)$.

\subsection{Measures}

\subsubsection{History of Child Abuse}

Information on history of child abuse was obtained through child protection services. Given the size of the group of children with a history of abuse, the option was to analyze this variable in two distinct ways: (a) dichotomized 
in present or absent; and (b) subdivided into four categories according to different types of abuse (cf. Barnett et al., 1993): without history of abuse, negligence only, and child abuse (all types of abuse, except negligence only). We also included an at-risk category with children referred in child protection services for exposure to deviant behaviors or to domestic violence.

\subsubsection{School Achievement}

School achievement was measured by children's grades and number of grade retentions (cf. Eckenrode, Laird \& Doris, 1993). The presence and number of grade retentions was reported by the students themselves. The mean grades in Language (Portuguese) and Math throughout the previous school year (2007-2008) were calculated based on school reports for each child in each trimester. In Portugal the grade system varies from 1 to 5 in $5^{\text {th }}-9^{\text {th }}$ grades, wherein 1-2 are falling grades and 3-5 passing grades. The overall mean grade for language was 2.90 ( $S D$ $=0.63)$, with no significant differences among grade levels. The overall Math mean grade was $2.82(S D=0.83)$; however, differences were statistically significant with a lower Math mean for $7^{\text {th }}$ graders $(M=2.31)$ and higher for $5^{\text {th }}$ graders $(M=3.10)$.

\subsubsection{Perceived Social Support}

The Social Support Appraisals Scale: Child's Subjective Appraisal of Family, Peer and Teacher Support (SSAS) was used. This is a 41-item self-report instrument developed by Dubow and Tisak (1989). Items are rated on a 5-point Likert scale, from 1 (never) to 5 (always), wherein some are reverse-coded. In total, 19 items assess peer support from friends and classmates (e.g., Some kids feel left out by their friends, but other kids don't. Do you feel left out by your friends?); 12 items evaluate family support (e.g., Some kids can count on their family for help or advice when they have problems, but other kids cannot. Can you count on your family for help or advice when you have problems?); and 10 items address the support provided by teachers (e.g., Some kids feel very close to their teachers, but other kids don't. Do you feel very close to your teachers?).

Its psychometric qualities were shown for the original versions (Dubow \& Ullman, 1989; Dubow et al., 1991) and for the Portuguese population (Lopes \& Moleiro, in press). In the present study, internal consistency values were of 0.90 for the scale and of $0.88,0.89$ and 0.83 for each of its components: peers, family and teachers, respectively. Factorial analysis was conducted revealing the scale's good quality through the values obtained in Kaiser-Meyer-Olkin Statistic $(K M O=0.87)$ and in Bartlett's Sphericity Test $(B=5613.35 ; p<0.01)$, explaining $39.96 \%$ of the total variance obtained, with explanation values varying from $10.36 \%$ and $15.46 \%$ for each factor. All items showed agreeing factor loadings with the ones obtained by the original authors (Dubow \& Ullman, 1989; Dubow et al., 1991).

\subsubsection{Demographic Information}

After filling out the SSAS, students were asked to fill out a brief sheet with demographic information, which included age, gender, ethnicity, family composition, grade level and number of retentions. Given that self-report by the student may be unreliable for socioeconomic status indicators, SES was assessed by obtaining information on financial support provided to the families in school social services. Three broad levels were defined - low, low average, and high average or good - for families qualified for full financial support, partial financial support, and families no financial support, respectively.

\subsection{Procedure}

The questionnaires were applied in the children's classrooms in a school in a small urban area in Lisbon's suburbs, after obtaining informed consent from all participants (including children and their parents), according to ethical principles (American Psychological Association, 2002). As indicated by the authors of the original scale, each item was read aloud while the researcher checked that all the children understood and were following directions, not skipping ahead nor falling behind (Dubow \& Ullman, 1989; Dubow et al., 1991).

\section{Results}

\subsection{Child Abuse and School Achievement}

Children with history of abuse showed significantly lower Language $(t(384)=5.55 ; p<0.01)$ and Math grades $(t(384)=4.77 ; p<0.01)$, as well as more retentions $(t(384)=-4.14 ; p<0.01)$, when compared with children without history of abuse. Analysis of variance (ANOVA's) revealed significant relationships between types of abuse and school achievement for all measures studied: Language $(F(3,401)=11.18 ; p<0.01)$ and Math grades $(F(3,401)=9.12 ; p<0.01)$ and number of retentions $(F(3,401)=11.95 ; p<0.01)$. Neglected children showed lower Language and Math grades and more years of retention than children without history of abuse. These significant differences were also found when comparing children without or with history of abuse, with the latter 
showing poorer school adjustment. Differences between at-risk children and any other group were not found for any of the measures studied. These results are represented in Figure 1.

\section{Insert Figure 1}

There were no significant differences among children from Portuguese or ethnically minority backgrounds in school achievement in Language, Math and number of retentions. However, a significant difference was found regarding SES on Language $(F(2,389)=5.93 ; p<0.01)$ and Math $(F(2,389)=7.88 ; p<0.01)$ results, but not on retentions. SES was, hence, used as a co-variable.

\subsection{Child Abuse and Social Support}

History of abuse did not relate significantly to social support, for any of the sources studied - peers $(t(377)=$ $-0.44, n s)$, family $(t(377)=0.20, n s)$ and teachers $(t(376)=-0.96, n s)-$ neither for global social support $(t(377)$ $=-0.50, n s)$. All children revealed moderately high perceived social support with medium values all above 3.54 (range: 1-5). ANOVA's also did not show differences in perceived support between any of the types of abuse global social support $(F(3,401)=0.74, n s)$, support from peers $(F(3,401)=0.40, n s)$, family $(F(3,401)=0.62$, $n s)$ and teachers $(F(3,401)=1.96, n s)$. Therefore, the variable was dichotomized in high and low perceived support, divided by its median values (cf. Demaray \& Malecki, 2002a), but still no significant differences for any of the scale's dimensions were found: peers $(t(360)=0.24, n s)$, family $(t(353)=-0.34, n s)$, teachers $(t(358)=$ $-0.60, n s)$ and global support $(t(367)=0.29, n s)$. Nonetheless, results for perceived social support differed according to the three sources analyzed, with children perceiving higher support from their family $(M=4.36)$, followed by their peers $(M=3.79)$ and finally their teachers $(M=3.54)$. The repeated measures ANOVA indicated differences between groups $(F(20,390)=213.76 ; p<0.01)$ were statistically significant. The multiple means comparison, with Bonferroni adjustment, indicated differences among all groups: peers-family, peers-teachers, and family-teachers support.

\subsection{Social Support and School Achievement}

Social support (dichotomized) related significantly with school achievement, i.e., children with higher perceived global social support presented significantly higher school results than children with lower perceived social support, both in Language $(t(380)=-3.34 ; p<0.01)$ and Math $(t(380)=-3.20 ; p<0.01)$, as well as less retentions $(t(380)=1.93 ; p=0.05)$. A significant relationship between perceived family support and retentions $(t$ $(366)=2.74 ; p<0.01)$ was also found, but not with Language $(t(366)=-1.87, n s)$ or Math $(t(366)=-1.39, n s)$ results. Significance between perceived teacher support and all measures of school achievement was found: Language $(t(369)=3.22 ; p<0.01)$ and Math $(t(369)=-5.46 ; p<0.001)$ results and number of retentions $(t$ $(369)=-4.27 ; p<0.001)$. All results indicated a favorable relationship between perceived social support and school achievement. No differences were found for perceived peer support on any of the school achievement measures.

Aforementioned results were independent of children's ethnic background and SES.

\subsection{Child Abuse, Social Support and School Achievement - Moderation Effects}

Moderation effects were investigated using ANCOVA's, using subtypes of child abuse as independent variable, social support (low or high) as covariate, and school achievement measures as dependent variables. A moderation effect of perceived social support was found in the relationship between child abuse and Language results $(F(3)=3.26 ; p<0.05)$ (Figure 2$)$.

\section{Insert Figure 2}

The analyses of simple effects revealed that it was significant for the group of children without history of abuse $(F(1,381)=7.46 ; p<0.01)$ and at-risk $(F(1,381)=13.24 ; p<0.01)$, with higher perceived social support related to better school results. However, the difference was not significant for neglected children $(F(1,381)=$ $0.23, n s)$, nor children from the child abuse group $(F(1,381)=0.01, n s)$. It also was not significant for any of the support sources studied: peers $(F(3,381)=2.26, n s)$, family $(F(3,381)=0.14, n s)$ and teachers $(F(3,381)$ $=1.03, n s)$.

Similarly, a significant positive moderation social support effect in Math results was found $(F(3,381)=3.26 ; p<$ $0.05)$. This effect was observed for non-abused children $(F(1)=5.63 ; p<0.05)$ and for at-risk children $(F(1$, $381)=13.58 ; p<0.001)$, but did not reach statistical significance for neglected children $(F(1,381)=2.55, n s)$ or children from the child abuse group $(F(1,381)=0.03, n s)$ (Figure 3$)$

\section{Insert Figure 3}

As for each of the support sources studied, peer support also functioned as a moderation variable between child 
abuse and Math results $(F(3,381)=2.79 ; p<0.05)$, but not family $(F(3,381)=0.64, n s)$ nor teacher support $(F$ $(3,381)=1.84, n s)$. More specifically, the moderation effect was found for at-risk children $(F(1,381)=6.35 ; p$ $<0.05$ ) (Figure 4).

\section{Insert Figure 4}

A moderation effect of perceived social support was also found in the relationship between history of abuse and number of grade retentions $(F(3,381)=2.57 ; p=0.05)$. The simple effect was significant for non-abused children $(F(1,381)=7.00 ; p<0.01)$. It was not significant for neglected children $(F(1,381)=3.20, n s)$, nor for at-risk children $(F(1,381)=0.14, n s)$ nor for children from the child abuse group $(F(1,381)=1.05, n s)$.

However, as can be observed in Figure 5, the most striking difference found for this school achievement measure was that perceived social support did not seem to relate to school success, but instead, school maladjustment (higher number of retentions) for children from the negligence and child abuse groups. In fact, children from these two groups with high perceived social support had more retentions than children with low perceived social support.

\section{Insert Figure 5}

When sources of support were explored, only peer support did not have a moderation effect in the relationship between child abuse and grade retentions $(F(3,381)=0.42, n s)$. Both family $(F(3,381)=2.87 ; p<0.05)$ and teacher support $(F(3,381)=4.51 ; p<0.01)$ showed significant moderation between these two variables.

Family support showed a statistically significant simple effect for non-abused children $(F(1,381)=11.48 ; p<$ $0.01)$, while it did not reach statistical significance for any of the other groups: at-risk $(F(1,381)=3.00, n s)$, negligence $(F(1,381)=2.75, n s)$ and child abuse $(F(1,381)=0.25, n s)$ (Figure 6). As for teacher support, a significant moderation effect was found for non-abused $(F(1,381)=21.21 ; p<0.001)$ and for neglected $(F(1$, $381)=5.47 ; p<0.05)$ children (Figure 7). Simple effects did not reach significance for at-risk children $(F(1$, $381)=0.10, n s)$ and child abuse groups $(F(1,381)=0.07, n s)$. As in the case of the perceived global social support, perceived family support and teacher support were associated with children's higher number of retentions, instead of school adjustment, but only among neglected children and adolescents.

Insert Figures 6 and 7

\section{Discussion}

The main goal of the present study was to explore the moderation effect of perceived social support on the relationship between of child abuse history and school achievement. Findings revealed a moderation effect of social support in the relationship between history of abuse and school achievement, although significant differences were mainly found for children without history of abuse. Therefore, it is not possible to confirm the hypotheses that perceived social support always exerts a positive moderation effect between child abuse and school achievement. In other words, results support only partially the adaptability of the social support as a moderator of life stress model to the specific context of child abuse and school achievement.

For children without history of abuse, the moderation effect of global social support was found in all school achievement measures, and also of family and teacher support for number of grade retentions. For at-risk children, perceived support showed to have a significant moderation effect for Language and Math results. For this group, peer support also functioned as a buffer for Math results. For neglected children, teacher support was a significant moderation variable for number of grade retentions. No significant effect was found for abused children.

Results may suggest the existence of a critical level in risk situations experienced by children. Similarly to social support critical levels, as defended by Demaray and Malecki (2002a), for children without history of abuse and at-risk children, having high levels of perceived support seems to function in favor of their school adjustment. However, for children with past or present history of abuse, i.e., for the children with history of negligence and/or history of abuse, perceived social support may no longer be enough to promote educational adjustment.

Indeed, what seems to make results differ the most from others found in the same field of investigation is the direction in the moderation effect between history of abuse and school achievement. When analyzing the number of grade retentions, results indicate perceived social support related with school maladjustment for neglected children and abused children. This effect was found for global support, family support and teacher support. Data showed an association between high perceived teacher support and a high number of grade retentions for neglected children. This effect was also found for family support and global social support.

Three main factors may have contributed for the results found. Firstly, it is important to clarify the relationship 
between child abuse and stress. Even though stress may be considered a consequence of child abuse (Runtz \& Schallow, 1997), that does not mean stress and child abuse are identical. In reality, given the consequences of child abuse for children's adjustment, social support possibly functions differently for abused children than it does for other studied stressful situations, such as divorce, loss of a friend, problems with a teacher, or death in the family (e.g., Dubow \& Tisak, 1989; Dubow et al., 1991; Dubow, Edwards \& Ippolito, 1997; Jackson \& Warren, 2000).

Secondly, the relationship between child abuse and attachment must be considered. In fact, abused children tend to show more difficulties in attachment (Cicchetti \& Toth, 2005), showing frequently insecure attachments with their caretakers (Crittenden, 1985). Given the importance of a secure attachment in early life for psychological and social adjustment (Ainsworth, Blehar, Waters \& Wall, 1978), and given that social support allows individuals to develop adaptive attitudes towards others (Cutrona, Cole, Colangelo, Assouline \& Russell, 1994), the availability of social support might not be clearly understood by children with history of abuse, therefore, it may not be a positive promoter of their adjustment.

Thirdly, one should consider the fact that the number of grade retentions was the school achievement measure that related the most with history of child abuse, with social support as a moderator. Children with retentions are usually children who are older, have attended school the longest and, thus, children who know their peers, teachers and other school professionals better, and vice-versa.

\subsection{Conclusions and Implications}

Despite the lack of some expected results, this study confirms child abuse as a risk factor (e.g., Cicchetti \& Toth, 2005; Eckenrode et al., 1993; Egeland, 1991; Pepin \& Banyard, 2006) and social support as a protective factor (e.g., Dubow \& Tisak, 1989; Elias \& Haynes, 2008; Hagen, Myers \& Mackintosh, 2005; Perkins \& Jones, 2004; Spaccarelli \& Kim, 1995) for school achievement. Schools should then focus their intervention on promoting social support for children and adolescents, by (a) promoting children's friendships and reducing negative effects of stressful family contexts (Schwartz, Dodge, Pettit, Bates \& Conduct Problems Prevention Research Group, 2000); (b) developing tutoring/mentoring programs (Barrera \& Prelow, 2000) or mediation programs (Bloomquist \& Schnell, 2002) aimed at promoting children's emotional and behavioral adjustment, as well as their school achievement (DuBois, Holloway, Valentine e Cooper, 2002) and their familial relationships (Grossman \& Rhodes, 2002); (c) training teachers to identify child abuse signals and symptoms, and to refer them to child protection services (Kenny, 2001, 2004; Yanowitz, Monte \& Tribble, 2003); (d) developing programs aimed at drawing in and involving parents in school life and in their children's learning and achievements (Price, Cowen, Lorion \& Ramos-McKay, 1988); (e) training parents on authoritative and positive parenting, adaptive parent-child interactions and functional family relationships (Bloomquist \& Schnell, 2002); (f) empower communities to become responsive towards children exposed to trauma, recognizing that exposure to traumatic situations constitutes a major obstacle in developing community connections (Banyard \& LaPlant, 2002); and (g) establishing partnerships with other community organizations and resources aimed at changing abused children's and their families' contexts and thus developing their well-being (Cicchetti, Toth \& Rogosch, 2000).

\subsection{Limitations of the Present Study}

Two main limitations of the present study should be referred. The first concerns the small dimension of the group of children with history of abuse, which may have contributed to lower power in comparative analyses and results found were not statistically significant. The second limitation concerns data collection which occurred in one school only, thus limiting the generalization potential of results found.

\subsection{Conclusions and Future Prospects}

On the other hand, a positive contribution was given to the investigation in the field of child abuse by analyzing school achievement throughout one school year and by introducing ethnic background and SES as variables in the analyses. Future research should gather more information about participant children (e.g., age of child abuse onset, frequency and duration of abuse episodes, severety, continuity over time, time gap between abuse occurrence and consequence assessment) and families (e.g., family income, family education, occupation) in order to allow for the exploration of social support effects given other co-variables. Furthermore, researchers could cross-validate results in child self-report social support scales with other instruments or methodologies, allowing for a more clear and accurate understanding of social support effects in the relationship between history of child abuse and school achievement. 


\section{References}

Ainsworth, M. D. S., Blehar, M. C., Waters, E., \& Wall, S. (1978). Patterns of attachment: A psychological study of the strange situation. Hillsdale, NJ: Erlbaum.

American Psychological Association (2002). Ethical principles of psychologists and code of conduct. Washington, DC: American Psychological Association.

Banyard, V. L., \& LaPlant, L. E. (2002). Exploring links between childhood maltreatment and empowerment. Journal of Community Psychology, 30 (6), 687-707. http://dx.doi.org/10.1002/jcop.10026

Barnett, D., Manly, J. T., \& Cicchetti, D. (1993). Defining child maltreatment: The interface between policy and research. In D. Cicchetti \& S. L. Toth (Eds.), Child abuse, child development, and social policy (pp. 7-74). Norwood, NJ: Ablex.

Barrera, M., \& Prelow, H. (2000). Interventions to promote social support in children and adolescents. In D. Cicchetti, J. Rappaport, I. Sandler \& R. P. Weissberg (Eds.), The promotion of wellness in children and adolescents (pp. 309-340). Washington, DC: CWLA Press.

Bloomquist, M. L., \& Schnell, S. V. (2002). Helping children with aggression and conduct problems. New York, NY: The Guilford Press.

Cicchetti, D., \& Toth, S. L. (2005). Child maltreatment. Annual Review of Clinical Psychology, 1, 409-438. http://dx.doi.org/10.1146/annurev.clinpsy.1.102803.144029

Cicchetti, D., Toth, S. L., \& Rogosch, F. A. (2000). The development of psychological wellness in maltreated children. In D. Cicchetti, J. Rappaport, I. Sandler \& R. P. Weissberg (Eds.), The promotion of wellness in children and adolescents (pp. 395-426). Washington, DC: CWLA Press.

Crittenden, P. (1985). Social networks, quality of child rearing, and child development. Child Development, 56, 1299-1313. http://dx.doi.org/10.2307/1130245

Cutrona, C. E., Cole, V., Colangelo, N., Assouline, S. G. \& Russell, D. W. (1994). Perceived parental social support and academic achievement: An attachment theory perspective. Journal of Personality and Social Psychology, 66 (2), 369-378. http://dx.doi.org/10.1037/0022-3514.66.2.369

Demaray, M. K., \& Malecki, C. K. (2002a). Critical levels of perceived social support associated with student adjustment. School Psychology Quarterly, 17 (3), 213-241. http://dx.doi.org/10.1521/scpq.17.3.213.20883

Demaray, M. K., \& Malecki, C. K. (2002b). The relationship between perceived social support and maladjustment for students at risk. Psychology in the Schools, 39 (3), 305-316. http://dx.doi.org/10.1002/pits.10004

Demaray, M. K., Malecki, C. K., Davidson, L. M., Hodgson, K. K., \& Rebus, P. J. (2005). The relationship between social support and student adjustment: A longitudinal analysis. Psychology in the Schools, 42 (7), 691-706. http://dx.doi.org/10.1002/pits.20120

DuBois, D., Holloway, J., Valentine, C., \& Cooper, H. (2002). Effectiveness of mentoring programs for youth: A meta-analytic review. American Journal of Community Psychology, 30 (2), 157-197. http://dx.doi.org/10.1023/A:1014628810714

Dubow, E. F., Edwards, S., \& Ippolito, M. F. (1997). Life stressors, neighborhood disadvantage, and resources: A focus on inner-city children's adjustment. Journal of Clinical Child Psychology, 26 (2), 130-144.

http://dx.doi.org/10.1207/s15374424jccp2602_2

Dubow, E. F., \& Tisak, J. (1989). The relation between stressful life events and adjustment in elementary school children: The role of social support and social problem solving skills. Child Development, 60, 1412-1423. http://dx.doi.org/10.2307/1130931

Dubow, E.F., Tisak, J., Causey, D., Hryshko, A., \& Reid, G. (1991). A two-year longitudinal study of stressful life events, social support, and social problem-solving skills: Contributions to children's behavioral and academic adjustment. Child Development, 62, 583-599. http://dx.doi.org/10.2307/1131133

Dubow, E. F., \& Ullman, D. G. (1989). Assessing social support in elementary school children: The survey of children's social support. Journal of Clinical Child Psychology, 18 (1), 52-64. http://dx.doi.org/10.1207/s15374424jccp1801_7

Eckenrode, J., Laird, M., \& Doris, J. (1993). School performance and disciplinary problems among abused and neglected children. Developmental Psychology, 29 (1), 53-62. http://dx.doi.org/10.1037/0012-1649.29.1.53 
Egeland, B. (1991). A longitudinal study of high-risk families: Issues and findings. In R. H. Starr \& D. A. Wolfe (Eds.), The effects of child abuse and neglect: Issues and research (pp. 33-53). New York, NY: Guilford Press.

Elias, M. J., \& Haynes, N. M. (2008). Social competence, social support, and academic achievement in minority, low-income, urban elementary school children. School Psychology Quarterly, 23 (4), 474-495. http://dx.doi.org/10.1037/1045-3830.23.4.474

Ezzell, C. E., Swenson, C. C., \& Brondino, M. J. (2000). The relationship of social support to physically abused children's adjustment. Child Abuse \& Neglect, 24 (5), 641-651. http://dx.doi.org/10.1016/S0145-2134(00)00123-X

Finkelhor, D. (1995). The victimization of children: A developmental perspective. American Journal of Orthopsychiatry, 65 (2), 177-193. http://dx.doi.org/10.1037/h0079618

Frazier, P. A., Tix, A. P., Klein, C. D., \& Arikian, N. (2000). Testing theoretical models of the relations between social support, coping and adjustment to stressful life events. Journal of Social and Clinical Psychology, 19, 314-335. http://dx.doi.org/10.1521/jscp.2000.19.3.314

Grossman, J., \& Rhodes, J. (2002). The test of time: Predictors and effects of duration in youth mentoring relationships. American Journal of Community Psychology, 30 (2), 199-219. http://dx.doi.org/10.1023/A:1014680827552

Hagen, K. A., Myers, B. J., \& Mackintosh, V. H. (2005). Hope, social support, and behavioral problems in at-risk children. American Journal of Orthopsychiatry, 75 (2), 211-219. http://dx.doi.org/10.1037/0002-9432.75.2.211

Hildyard, K. L., \& Wolfe, D. A. (2002). Child neglect: developmental issues and outcomes. Child Abuse \& Neglect, 26, 679-695. http://dx.doi.org/10.1016/S0145-2134(02)00341-1

Jackson, Y., \& Warren, J. S. (2000). Appraisal, social support, and life events: Predicting outcome behavior in school-age children. Child Development, 71 (5), 1441-1457. http://dx.doi.org/10.1111/1467-8624.00238

Jafee, S. R., Caspi, A., Moffitt, T. E., Polo-Tomás, M., \& Taylor, A. (2007). Individual, family, and neighborhood factors distinguish resilient from non-resilient maltreated children: A cumulative stressors model. Child Abuse \& Neglect, 31, 231-253. http://dx.doi.org/10.1016/j.chiabu.2006.03.011

Kaul, M., \& Lakey, B. (2003). Where is the support in perceived support? The role of generic relationship satisfaction and enacted support in perceived support's relation to low distress. Journal of Social and Clinical Psychology, 22, 59-78. http://dx.doi.org/10.1521/jscp.22.1.59.22761

Kenny, M. C. (2001). Child abuse reporting: teachers' perceived deterrents. Child Abuse \& Neglect, 25, 81-92. http://dx.doi.org/10.1016/S0145-2134(00)00218-0

Kenny, M. C. (2004). Teachers' attitudes toward and knowledge of child maltreatment. Child Abuse \& Neglect, 28, 1311-1319. http://dx.doi.org/10.1016/j.chiabu.2004.06.010

Kinard, E. M. (1999). Psychosocial resources and academic performance in abused children. Children and Youth Services Review, 21 (5), 351-376. http://dx.doi.org/10.1016/S0190-7409(99)00026-2

Kinard, E. M. (2001). Perceived and actual academic competence in maltreated children. Child Abuse \& Neglect, 25, 33-45. http://dx.doi.org/10.1016/S0145-2134(00)00219-2

Langford, C. P. H., Bowsher, J., Maloney, J. P., \& Lillis, P. P. (1997). Social support: a conceptual analysis. Journal of Advanced Nursing, 25, 95-100. http://dx.doi.org/10.1046/j.1365-2648.1997.1997025095.x

Lakey, B., \& Cassady, P. B. (1990). Cognitive processes in perceived social support. Journal of Personality and Social Psychology, 59, 337-343. http://dx.doi.org/10.1037/0022-3514.59.2.337

Lowenthal, B. (1998). The effects of early childhood abuse and the development of resiliency. Early Childhood Development and Care, 142, 43-52. http://dx.doi.org/10.1080/0300443981420105

Lopes, R. \& Moleiro, C. (in press). Avaliação do Suporte Social de Crianças e Jovens: Estudo de Validação da Escala de Percepção de Suporte da Família, Pares e Professores. In M. Calheiros, M. V. Garrido, \& S. Santos, Crianças em risco e perigo: Contextos, investigação e intervenção (Vol. 2). Lisboa: Edições Sílabo.

Muller, R. T., Gragtmans, K., \& Baker, R. (2008). Childhood physical abuse, attachment, and adult social support: Test of a meditational model. Canadian Journal of Behavioural Science, 40 (2), 80-89. http://dx.doi.org/10.1037/0008-400X.40.2.80

Owen, A. E., Thompson, M. P., Mitchell, M. D., Kennebrew, S. Y., Paranjape, A., Reddick, T. L., Hargrove, G. L., \& Kaslow, N. J. (2008). Perceived social support as a mediator of the link between intimate partner conflict and 
child adjustment. Journal of Family Violence, 23, 221-230. http://dx.doi.org/10.1007/s10896-007-9145-4

Pepin, E. N., \& Banyard, V. L. (2006). Social support: A mediator between child maltreatment and developmental outcomes. Journal of Youth and Adolescence, 35 (4), 617-630. http://dx.doi.org/10.1007/s10964-006-9063-4

Perkins, D. F., \& Jones, K. R. (2004). Risk behaviors and resiliency within physically abused adolescents. Child Abuse \& Neglect, 28, 547-563. http://dx.doi.org/10.1016/j.chiabu.2003.12.001

Price, R. H., Cowen, E. L., Lorion, R. P., \& Ramos-McKay, J. (1988). Model prevention programs: Epilogue and future prospects. In R. H. Price, E. L. Cowen, R. P. Lorion \& J. Ramos-McKay (Eds.), Fourteen ounces of prevention (pp. 187-191). Washington, DC: American Psychological Association. http://dx.doi.org/10.1037/10064-000

Runtz, M. G., \& Schallow, J. R. (1997). Social support and coping strategies as mediators of adult adjustment following childhood maltreatment. Child Abuse \& Neglect, 21 (2), 211-226. http://dx.doi.org/10.1016/S0145-2134(96)00147-0

Schwartz, D., Dodge, K. A., Pettit, G., \& Bates, J. E. (2000). Friendship as a moderating factor in the pathway between early harsh home environment and later victimization in the peer group. Developmental Psychology, 36 (5), 646-662. http://dx.doi.org/10.1037/0012-1649.36.5.646

Spaccarelli, S., \& Kim, S. (1995). Resilience criteria and factors associated with resilience in sexually abused girls. Child Abuse \& Neglect, 19 (9), 1171-1182. http://dx.doi.org/10.1016/0145-2134(95)00077-L

Tyler, K. A., Johnson, K. A., \& Brownridge, D. A. (2008). A longitudinal study of the effects on child maltreatment on later outcomes among high risk adolescents. Journal of Youth and Adolescence, 37, 506-521. http://dx.doi.org/10.1007/s10964-007-9250-y

Yanowitz, K. L., Monte, E., \& Tribble, J. R. (2003). Teachers' beliefs about the effects of child abuse. Child Abuse \& Neglect, 27, 483-488. http://dx.doi.org/10.1016/S0145-2134(03)00033-4

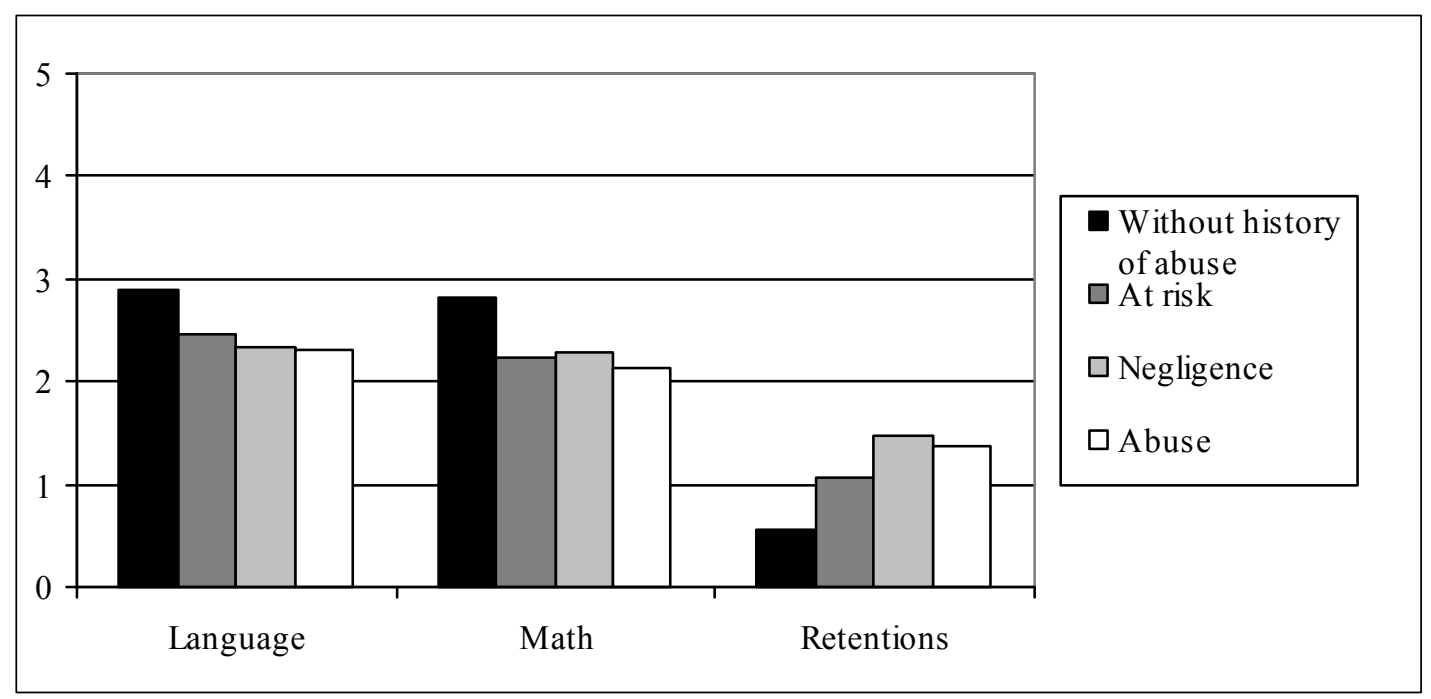

Figure 1. Mean results in language and math, and mean number of retention years by group 


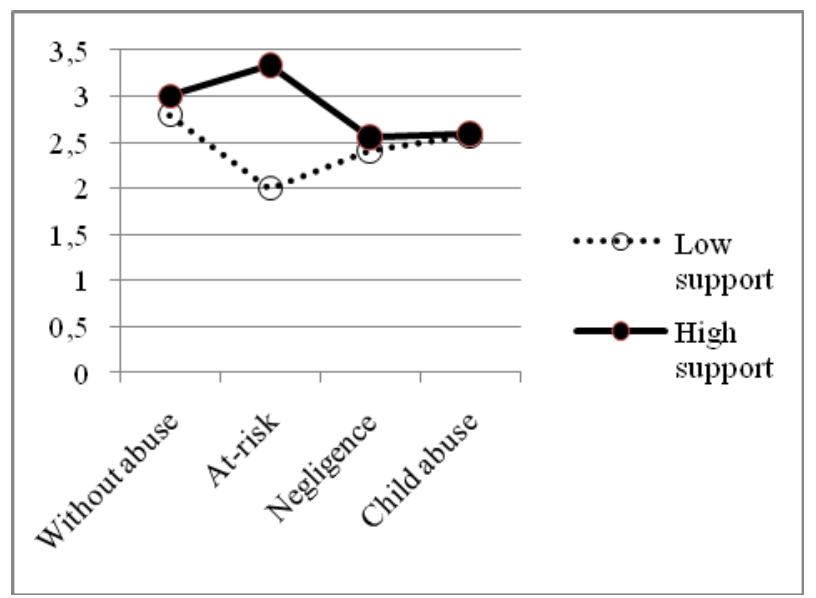

Figure 2. Effect of global social support on language results

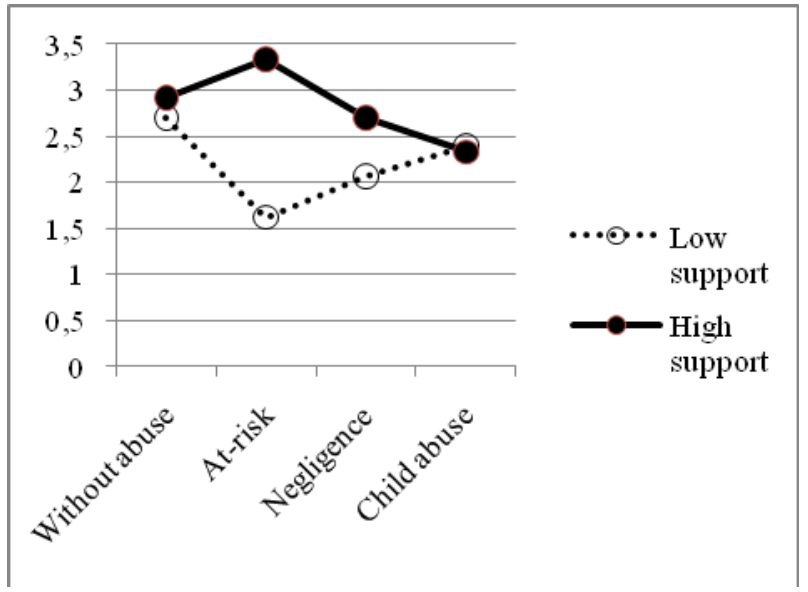

Figure 3. Effect of global social support on math results

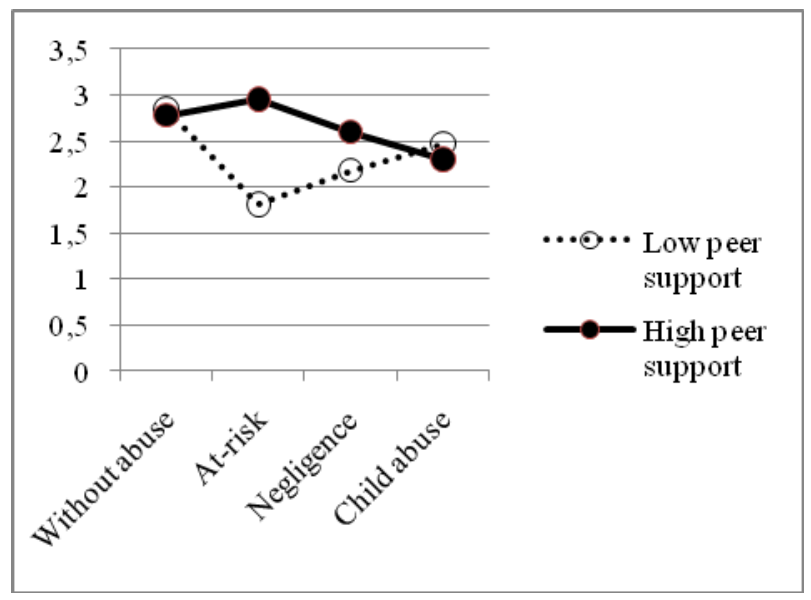

Figure 4. Effect of peer support on math results 


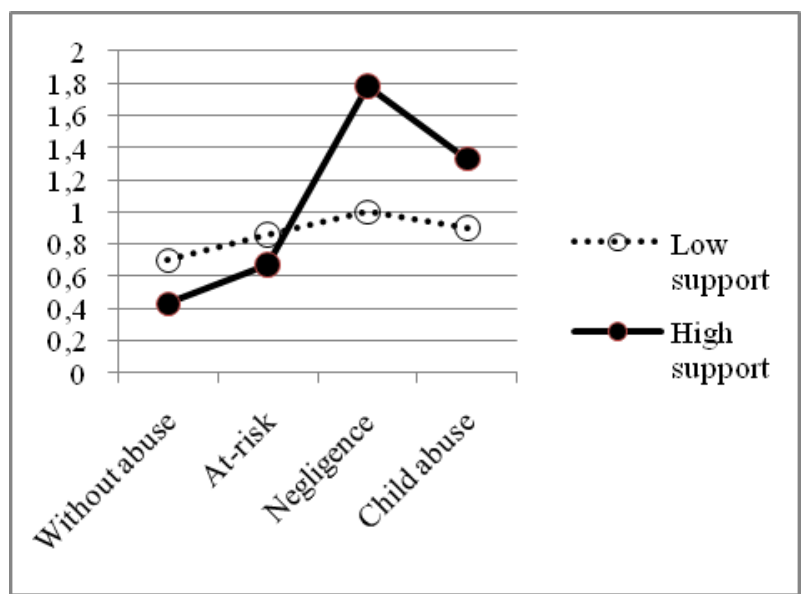

Figure 5. Effect of global social support on grade retentions

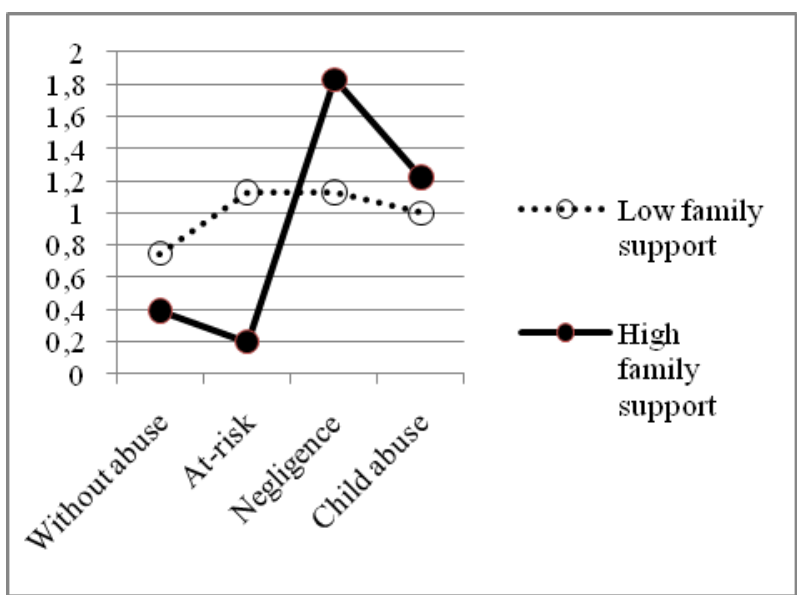

Figure 6. Effect of family support on grade retentions

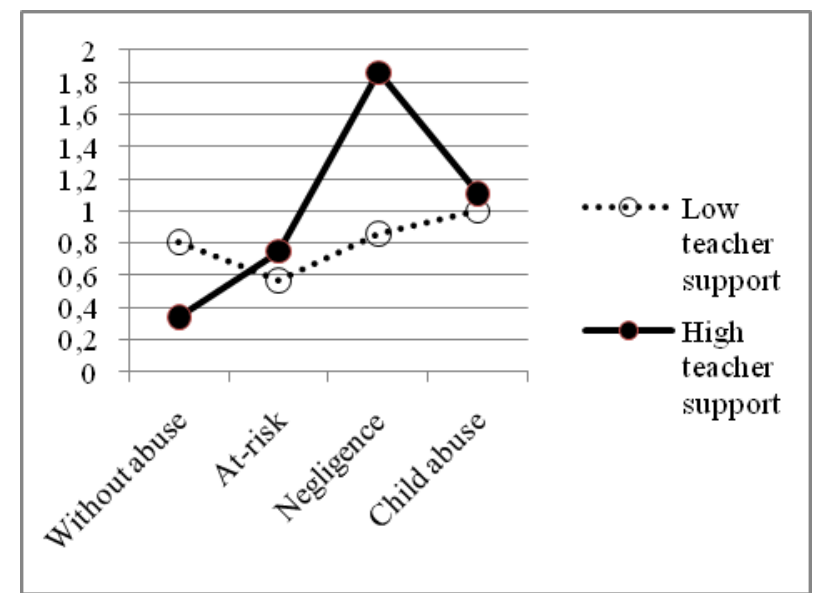

Figure 7. Effect of teacher support on grade retentions 